Aletria, Belo Horizonte, v. 27, n. 2, p. 15-33, 2017

\title{
Segredos escondidos à vista de todos: implicações para a leitura dos códigos de barras nos livros infantis
}

\author{
Secrets Hidden in the Sight of All: Implications \\ of the Reading of Barcodes in Children's Books
}

\author{
Ana Margarida Ramos \\ Universidade de Aveiro, Aveiro / Portugal \\ anamargarida@ua.pt
}

Resumo: Pretende-se, com este estudo, proceder a uma análise dos códigos de barras ilustrados em livros infantis, com vista a identificar as implicações para a leitura desta opção de design gráfico. A partir da identificação de um corpus de várias dezenas de livros infantis ilustrados, publicados em Portugal nos últimos anos, identificamse não só as manipulações visuais e artísticas de que estes elementos são alvo, mas também a forma como a sua leitura, nomeadamente com crianças, pode colaborar no desenvolvimento de competências profundas de leitura, além de permitir compreender a dimensão relevante dos peritextos na construção dos sentidos dos livros.

Palavras-chave: literatura infantil; design gráfico; livro-álbum; livro-objeto; materialidade; metaficção.

\begin{abstract}
This text aims at analysing illustration of barcodes in children's books in order to identify their implications in the process of reading this specific graphic design option. Based on a large number of illustrated children's books published in Portugal in the last few years, the essay discusses the visual and artistic transformations of the barcodes in illustrations and reflects upon the reading implications of these elements, especially for children. We argue that they promote the development of reading competences at an early stage, and help to understand the importance of peritexts in the construction of the meaning.
\end{abstract}

Keywords: children's literature; graphic design; picturebook; object-book; materiality; metafiction. 


\section{O contributo dos peritextos na literatura infantil: o livro como objeto}

O livro infantil conheceu, nos últimos anos, um investimento considerável, tornando-se um objeto artístico de eleição para criadores e leitores de diferentes faixas etárias. O desenvolvimento das artes gráficas, as possibilidades materiais da impressão, a formação cada vez mais especializada dos seus criadores, juntando autores do texto, das imagens e do objeto de design em que o livro se transformou, têm tido um impacto significativo na edição, que se tornou experimental, ousada e muito criativa. O livro infantil é hoje uma espécie de laboratório experimental de criação, cujos limites são desafiados de forma constante, quer em termos de conteúdo, quer no nível da forma. Pensado como um objeto único, o livro infantil é alvo de uma atenção a todos os detalhes que o integram, o que inclui elementos textuais e peritextuais, ${ }^{1}$ como a ilustração, o formato ou o tipo de papel.

No caso dos livros infantis ilustrados, tem sido visível o crescimento da ilustração ${ }^{2}$ para além do interior do volume, ocupando cada vez mais espaço, mas sobretudo assegurando a unidade e a coesão dos volumes, pensados como um todo, enquanto objetos artísticos. Díaz Armas refere-se à "capacidade amplificadora" da ilustração em relação ao texto, assim como ao evidente crescimento da componente imagética no domínio da publicação de destinatário infantil, ocupando vários espaços do livro. Trata-se, a nosso ver, de entender a ilustração como uma espécie de "caixa de ressonância", amplificando os sentidos do texto, ativando competências de leitura e ensinando a ler todos os elementos do livro, desenvolvendo a literacia em sentido plural e abrangente.

A presença de imagens em elementos peritextuais, ${ }^{3}$ como as guardas, ${ }^{4} \mathrm{a}$ folha de rosto ${ }^{5}$ e anterrosto, a ficha técnica, para além da capa e contracapa, ${ }^{6}$ é sintomática do seu relevo, mas também do

${ }^{1}$ Cf. GENETTE. Palimpsestes.

${ }^{2}$ Cf. DÍAZ ARMAS. Estratégias de desbordamiento en la ilustración de libros infantiles; DÍAZ ARMAS. El contrato de lectura en el álbum.

${ }^{3}$ Cf. RAMOS. Ilustrar para além das ilustrações.

${ }^{4}$ Cf. DÍAZ ARMAS. Estratégias de desbordamiento en la ilustración de libros infantiles; RAMOS. A ilustração para além da ilustração; SIPE; MCGUIRE. Picturebook Endpapers; LINDEN. Lire l'album.

${ }^{5} \mathrm{Cf}$. SOTTO MAYOR. As folhas de rosto.

${ }^{6}$ Cf. MATTOS; RIBEIRO; VIANNA. Capas e contracapas de livros ilustrados. 
significado de que se reveste a ilustração, antecipando informações e criando expectativas, dialogando igualmente com o interior do texto, acrescentando-lhe sentidos, ou até procedendo à sua paródia e ironia, numa espécie de autocomentário externo de cariz questionador. $\mathrm{O}$ seu interesse do ponto de vista do desenvolvimento de competências de leitura pode ser suscitado pelo mediador, explicitando as relações entre os elementos textuais e peritextuais, numa lógica de iniciação dos leitores nos protocolos de leitura do texto literário, entendida como um jogo de descoberta constante, em função da ação cooperante de leitores ativos.

Esta questão dos peritextos que envolvem o livro infantil, e que interferem no pacto de leitura que ele estabelece com os leitores, estende-se a elementos considerados acessórios e dispensáveis, como as cintas, já estudadas por Margareth Mattos, no âmbito da literatura institucionalizada ${ }^{7}$ e infantil, ${ }^{8}$ chamando a atenção para as implicações de todos os elementos no processo de leitura e de construção de sentidos do livro, mas também para a alteração das suas funções principais, já que a cinta, sendo habitualmente um elemento promocional, pode tornar-se um elemento integrante do sistema comunicativo do livro. E se os peritextos principais, como a capa e a contracapa, para além da materialidade associada ao formato, ao papel ou ao tipo de capa, por exemplo, são sobretudo relevantes no que concerne à criação de expectativas e à realização de antecipações sobre o conteúdo do volume, outros peritextos, como as guardas ou mesmo os códigos de barras, como veremos, ao serem alvo de uma exploração atenta no final do processo de leitura, funcionam como resumo, continuação ou questionamento do conteúdo, comentando-o, prolongando a leitura para lá do seu terminus.

\section{$O$ código de barras: da funcionalidade identificativa à sugestão metaficcional}

O código de barras é uma representação gráfica de dados numéricos e alfanuméricos que descreve e caracteriza o objeto ao qual surge associado, de características unidimensionais. Formado por linhas verticais paralelas, que variam em espessura e distância, o código

\footnotetext{
${ }^{7}$ Cf. MATTOS. As cintas e seus contratos de comunicação.

${ }^{8} \mathrm{Cf}$. MATTOS. Escritores consagrados, ilustradores renomados, palavra e imagem entrelaçadas.
} 
barras permite a leitura ótica por parte de scanners específicos, sendo o reconhecimento da informação automatizado. Conhecidos pelo uso nos estabelecimentos comerciais, permitindo a identificação mais rápida dos produtos no momento do pagamento, têm sobretudo utilidade em termos de facilidade e simplicidade de ações de reconhecimento e identificação de produtos e objetos, estando o seu uso globalizado e adequado a outros contextos, como a identificação de pacientes nos sistemas de saúde, de utilizadores de serviços (espetáculos, viajantes), de encomendas e correspondência nos correios ou de malas num aeroporto. É evidente que os dados associados a um código de barras podem ser muito variados e permitem diversas aplicações, mas a sua funcionalidade identificativa, uma espécie de $\mathrm{ADN}$ dos objetos ou pessoas, é o aspeto transversal à sua utilização.

Nos livros infantis ilustrados, os códigos de barras, de presença obrigatória, além de identificarem o ISBN e outros dados bibliográficos das publicações, podem ser alvo de trabalho de design, que lhes permite ganhar novas funcionalidades, em tudo semelhantes às de outros peritextos, ${ }^{9}$ como as guardas, as folhas de rosto e fichas técnicas e as cintas. Mais ou menos invisíveis ao olhar dos leitores, pouco atentos a estes elementos, os códigos de barras ilustrados chamam a atenção dos leitores sobre si mesmos e sobre o livro que identificam, estabelecendo com ele vários tipos de relações. Este elemento surge referido de forma pontual em alguns trabalhos, ${ }^{10}$ com destaque para uma análise de capas e contracapas de livros-álbum, referindo, a propósito de um volume concreto, a alteração de funções do código de barras: "investe-se de outros sentidos, tornando-se parte integrante de uma ilustração e, com isso, reforçando o curioso jogo de ambiguidades que sustenta o texto verbo-visual da obra". ${ }^{11}$ Em alguns blogues estrangeiros, ${ }^{12}$ é possível encontrar algumas entradas que identificam exemplos de códigos de barras ilustrados, sendo um dos mais relevantes o levantamento de Travis Jonker, intitulado "Gallery: The Art of the Picture Book Barcode", sobre

\footnotetext{
${ }^{9}$ Cf. HIGONNET. The playground of the peritexts; DAVIE. Are You Talking to Me?; ROZARIO. Consuming books.

${ }^{10} \mathrm{Cf}$. LUZ. Do projecto à edição infantil; SANTOS. O influxo da mudança no álbum ilustrado.

${ }^{11}$ MATTOS; RIBEIRO; VIANNA. Capas e contracapas de livros ilustrados, p. 358.

${ }^{12}$ Cf. SAUER. Picture Book Barcode Bonanza.
} 
o qual Marge Loch-Wouters afirmou que "ele [o autor] destacou uma tendência artística deliciosa, quase secreta - códigos de barras em livros infantis transformados em arte" ${ }^{13}$ Este cariz "secreto" desta tendência crescente dos livros infantis foi o ponto de partida para este estudo, sobretudo quando este segredo está escondido à vista de todos que o saibam descobrir.

Uma análise de cerca de uma centena de títulos, portugueses e estrangeiros, estes últimos com e sem edição em Portugal, cujos códigos de barras apresentam algum tipo de alteração à disposição habitual deste identificador, permite-nos propor a seguinte tipologia relativa ao uso diferenciado da sua função básica, necessariamente provisória, a exigir mais análises (ou, eventualmente, um alargamento do corpus que suportou esta primeira aproximação):

1. códigos de barras ilustrados ou manipulados graficamente, com alteração de sua forma tradicional;

2. códigos de barras incorporados na ilustração da contracapa:

a. como elemento central da ilustração;

b. "ocultos" ou disfarçados numa ilustração de maiores dimensões.

A manipulação destes elementos resulta ainda em leituras diferentes, que ora parecem querer apagar o código de barras da contracapa, ocultando-o, através do disfarce, no contexto onde se insere, ora parecem destacá-lo, no espaço, conferindo-lhe centralidade e protagonismo. No primeiro caso, pode bastar a alteração do local habitual ou da orientação para produzir efeito. Trata-se, em todo o caso, de estratégias assumidamente metaficcionais, na medida em que fazem incidir a atenção do leitor num elemento externo à narrativa (e à própria literatura), mas que é investido de valor significante, questionando as fronteiras da ficção. Em qualquer dos casos, é possível que estes elementos passem a desempenhar novas funções e a possuir diferentes significados, sendo igualmente evidente, por vezes, o destaque explícito para a sua funcionalidade identificadora, nomeadamente através do questionamento da sua presença.

\footnotetext{
13 “ $[\ldots]$ he spotlighted a delightful, almost secret, artistic trend - barcodes on children's books incorporated into the art" (LOCH-WOUTERS. The Art of the Picture Book Barcode, tradução nossa).
} 
Sublinhe-se que o desafio gráfico que os códigos de barras suscitam não é exclusivo dos livros infantis, mas tem-se estendido a outros produtos, provando que não há limites para a criatividade e inventividade dos designers. Surgindo em embalagens de vários produtos, os códigos de barras passam a funcionar, além de identificadores, como promotores da sua imagem, atuando na promoção dos produtos.

\section{Análise de exemplos do panorama literário português}

\section{Traduções e clássicos}

A ilustração dos códigos de barras é mais frequente (mas não exclusiva) em livros-álbum, na medida em que se trata de publicações cuja construção, pensada como um todo, aposta de forma intensa na materialidade, sublinhando a relação entre o conteúdo e a forma, o texto (quando presente) e as ilustrações. Num verdadeiro livro-álbum de qualidade, sobretudo naqueles que melhor espelham os desenvolvimentos pós-modernos desta modalidade editorial, nenhum elemento que o integra é deixado ao acaso e o designer gráfico (às vezes o próprio diretor artístico editorial) colabora de forma assídua na construção final de um produto claramente multimodal. Nesta medida, não é estranho que as propostas mais interessantes que nos chegam de códigos de barras ilustrados em obras traduzidas venham assinadas por alguns dos mais criativos cultores contemporâneos deste formato, como Emily Gravett, Anthony Brwone, Gilles Bachelet ou Shaun Tan, só para dar rapidamente alguns exemplos de nomes conhecidos.

Na maior parte dos casos, a ilustração dos códigos de barras é incorporada na ilustração da contracapa, assumindo novas funcionalidades, podendo surgir como um objeto com relativa autonomia. Em geral, a ideia é "esconder" o código de barras, disfarçando a sua presença na ilustração, dado o seu caráter externo (além de repetitivo) à construção visual. De presença obrigatória, até em resultado de imposições legais e comerciais, pode constituir um obstáculo à completa fruição das páginas, transformando-se a sua manipulação num desafio e também num jogo com o leitor e a sua atenção, como alguns casos exemplificam. A dimensão irónica ou assumidamente cómica de algumas propostas constitui, assim, um exercício de leitura adicional ou complementar, estendendo o processo de interpretação para além dos seus limites habituais. 
Finalmente, veja-se como a ilustração destes elementos decorre de opções mais individuais do que editoriais, analisando a sua presença muito esporádica em editoras dedicadas ao livro-álbum, como a Kalandraka ou a OQO, onde foi difícil encontrar exemplos de manipulação, para além de Perto, de Natalia Colombo, e A bruxa arreganhadentes, de Tina Meroto e Maurizio A. C. Quarello. Trata-se, em ambos os casos, da incorporação dos códigos numa ilustração de maiores dimensões, ocupando toda a contracapa ou mesmo a capa e a contracapa trabalhadas como página dupla em termos de sentido. O caso mais original é, talvez, o de um livro-álbum recente, $O$ piolho sabe que, texto de Mathis e ilustrações de Aurore Petit, onde o código de barras vê as suas linhas prolongadas, aparentemente transformadas em fios de cabelo, servindo de "esconderijo" ao protagonista, nesta publicação que explora efeitos de zoom e de perspetiva na interpretação do real, conduzindo o leitor a questionar as aparências.

\section{Autoria portuguesa}

À exceção do caso da editora Planeta Tangerina, que tem apostado, na grande maioria das publicações, como veremos, no tratamento gráfico dos códigos de barras, inserindo-os nas ilustrações das capas, a atenção por parte de outros criadores e/ou chancelas editoriais, a este elemento é pontual e decorre quase sempre de casos isolados, fruto, cremos, da vontade expressa de ilustradores ou designers. Ainda assim, merece referência um conjunto de publicações que, podendo não ser exaustiva, ilustra as potencialidades criativas deste elemento. Todos os volumes da coleção Ler para Crer, da Nelson de Matos Edições, incluem sempre um código de barras ilustrado e recortado, com a forma de um pato, em estreita relação com a temática animal, que percorre os volumes cujo texto é assinado por Francisco Alegre Duarte e as ilustrações são de Cláudia Mariz Correia. Carla Pott, por exemplo, ou Luís Henriques já recorreram à ilustração dos códigos de barras em alguns volumes que ilustraram, integrando-os de forma natural nas ilustrações. Enquanto a primeira, em Pedro pescador (texto de José Viale Moutinho), explora habilmente a expressividade das cores fortes e contrastantes e das formas contornadas, maioritariamente redondas, dominadas por sugestões de cariz cómico, o segundo, em $O$ tempo canário e o Mário ao contrário (texto de Rita Taborda Duarte), limita-se a equilibrar a imagem da contracapa, trabalhando a posição do código de barras e o fundo. 
Os códigos de barras podem integrar as ilustrações de um livro, aproveitando a sua forma, o traçado paralelo das várias linhas, explorando possibilidades significativas variáveis, como aconteceu recentemente com a publicação Aqui há gato! (Figura 1), de Rui Lopes e Renata Bueno, que recorre a estes elementos em todas as imagens, desafiando a sua capacidade de encontrar novas utilidades, numa espécie de aproveitamento e recombinação da forma, convertida em padrão.

FIGURA 1 - Capa de Aqui há gato!

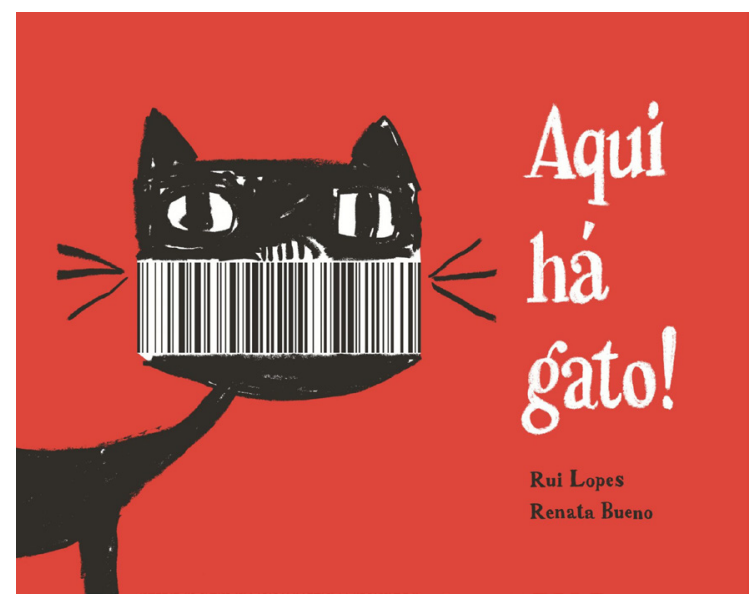

Fonte: LOPES. Aqui há gato!

A ilustradora do volume confessa que é o código de barras que está na base de toda a criação do livro: "Quis transformar uma coisa monótona, os códigos de barras, em imagens criativas", disse, em entrevista ao Público. ${ }^{14}$ Curiosamente, os códigos de barras usados nas ilustrações continuam a permitir a sua "leitura", original, remetendo para outros livros, se usarmos o descodificador apropriado. É, assim, possível encontrar obras traduzidas, como Quero o meu chapéu, de Jon Klassen, Art \& Max, de David Weisner, O Capuchinho Vermelho, de Charles Perrault, revisitado por Clémentine Sourdais ou Quero um abraço, de Simona Ciraolo, portuguesas, como Outono, de André Letria, ou outras não disponíveis no mercado nacional, como Tsunami, de Joyeb Chitrakar, Eventually Everything Connects, de Loris Lora, Space Race, de Tom

\footnotetext{
${ }^{14}$ PIMENTA. Um rei chato que acabou a tomar banhos de sol.
} 
Clohosy Cole, e ABcédaire, de Estellon Pascal, além de clássicos como Après le pont noir, de Kveta Pacovská.

Desta forma, a intertextualidade constrói-se por uma alusão ou citação muito original, transformando também o processo de leitura do texto, das imagens e dos códigos de barras.

Relembre-se, igualmente, o caso da incorporação de um código de barras numa ilustração do livro-álbum O Cuquedo, texto de Clara Cunha e ilustrações de Paulo Galindro, ao lado da zebra, parodiando, pelo uso das riscas, o padrão do animal, também ele convertido numa espécie de natural código de barras, na medida em que as suas riscas são sempre diferentes, funcionando como individualizantes e distintivas.

\section{O caso da editora Planeta Tangerina}

No panorama português, destaca-se, no recurso à ilustração dos códigos de barras, a editora Planeta Tangerina que, de forma regular e assídua, vem explorando as potencialidades deste elemento. Aliás, os primeiros volumes desta chancela tinham sempre uma proposta diferenciada de códigos de barras, aspeto que, a par do formato, parecia dar coesão às suas publicações. Imagem de marca da editora, a ilustração dos códigos de barras constitui, assim, mais a norma do que a exceção nos livros desta chancela, configurando um elemento identificador das suas publicações.

As opções de manipulação deste elemento são várias e os livros publicados ao longo de uma década exprimem não só o cuidado com o objeto-livro, mas também o posicionamento da editora face aos seus produtos, entendidos enquanto obras de arte pensadas como um todo, suscetíveis de várias leituras e destinadas a públicos muito variados (em termos de idade, interesses, formação etc), sem deixarem de ser também objetos de entretenimento, com os quais é possível brincar (também do ponto de vista da construção).

Uma análise das publicações desta editora ao longo dos anos permite constatar que a grande maioria dos volumes inclui algum tipo de manipulação do código de barras, desde a alteração da sua orientação na página, até à sua recriação visual, construindo uma nova imagem que os singulariza, chegando ao ponto de ser a única imagem da contracapa, passando pela sua transformação através do recorte e também pela sua incorporação em ilustrações de grandes dimensões, disfarçando ou ocultando a sua presença na página. 
O primeiro caso integra volumes como $O$ primeiro gomo $d a$ tangerina, Ir e vir e Com o tempo (Figura 2). Nos três exemplos a orientação do código de barras, seja vertical ou diagonal, procura acompanhar as linhas dominantes da imagem, repetindo, no primeiro caso, o paralelismo das linhas, ou, nos outros, uma disposição semelhante a outros elementos. Refira-se que estes casos não mereceriam atenção particular se não tivesse previamente sido identificada uma estratégia sistemática de tratamento deste elemento. Veja-se, assim, como o recurso prévio à ilustração de códigos de barras tem implicações na leitura destes elementos em livros posteriores, condicionando a atenção que lhes é dedicada e a sua interpretação. Trata-se de um exemplo evidente de desenvolvimento e aprofundamento de competências de leitura, na medida em que o olhar do leitor é (ou passa a ser) educado para dar atenção a elementos novos.

\section{FIGURA 2 - Contracapa do livro Com o tempo}

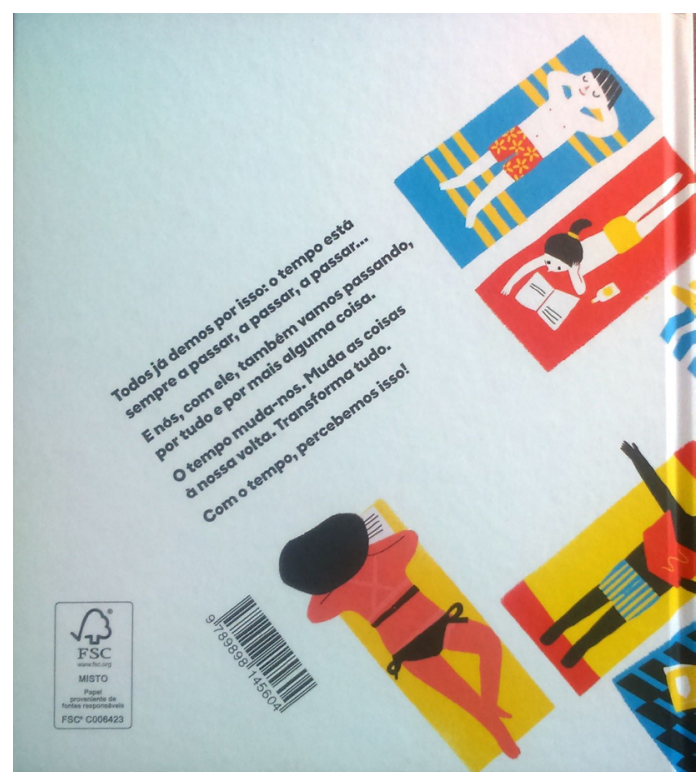

Fonte: MARTINS. Com o tempo.

O recurso a códigos alterados, através do recorte, surge em volumes como Este livro está a chamar-te, Finalmente o verão ou Imagem, entre outros. Nestes casos, o código, através da nova forma 
e recorte, consegue estabelecer um diálogo temático com o livro, funcionando como um eco da mensagem, uma metonímia ou uma alusão. Por exemplo, em Enquanto o meu cabelo crescia, o código é transformado em fios de cabelo e alvo de corte na diagonal, por parte de uma tesoura vermelha, repetindo e resumindo o elemento central da narrativa. Em Uma onda pequenina, o código surge também ondulante, recuperando o próprio título ou, em $A$ ilha (Figura 3), é transformado num vulcão, que expele lava, sugerindo, possivelmente, a solução para o problema da ilha, cujo relevo foi alterado para construir a ponte. Mais ou menos sutis, estas transformações passam a ser, para os leitores atentos, espaço de questionamento e reflexão, procurando as ligações com o conteúdo das narrativas, prolongando o processo de interpretação.

FIGURA 3 - Contracapa do livro $A$ ilha

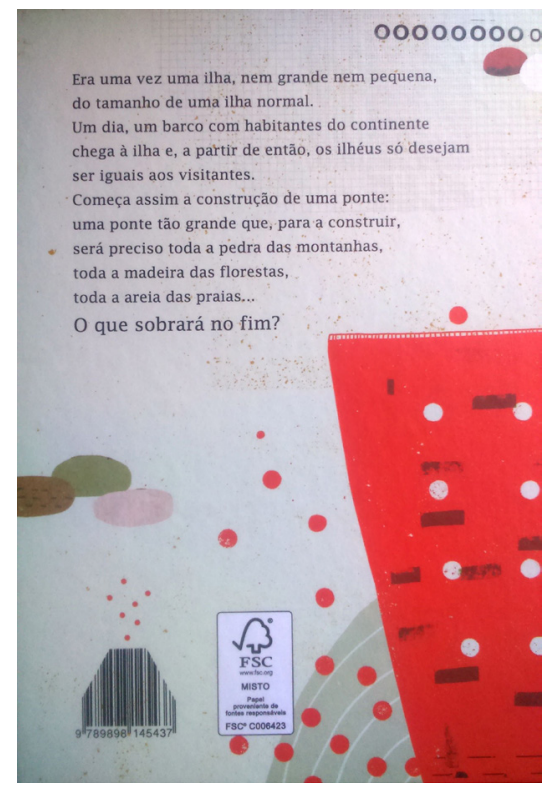

Fonte: ABREU. A ilha.

No caso dos códigos ocultos em ilustrações de maiores dimensões, é geralmente tirado partido da sua forma geométrica, o que permite que possa assumir outros significados, como uma janela, um frasco ou um armário de cozinha (ver respetivamente os casos de $O$ meu vizinho é uma cão, Batata Chaca Chaca (Figura 4) e Cá em casa somos...). Uma 
vez sobreposto a outros elementos, ou associado a formas semelhantes, o código de barras dilui-se na página, ocupa espaços, orientações e localizações diferentes, exigindo ao leitor atenção na sua identificação. Às vezes, o código é apenas ocultado por um contexto, sem que haja praticamente manipulação real e efetiva deste elemento. É a adição de outros elementos visuais (formas, letras, símbolos vários), semelhantes ou parecidos, que o ocultam, funcionando como uma espécie de camuflagem, como acontece em Trocoscópio, Conta-quilómetros ou Trava-línguas. Também é de ocultação ou disfarce que falamos no caso de Mary John, o romance mais recente de Ana Pessoa. O livro integra uma sobrecapa amovível e desdobrável, que se transforma num pôster, e o código de barras foi habilmente introduzido na alça do top da protagonista, sendo quase invisível ao primeiro olhar, também em resultado da presença de muitas linhas verticais no desenho do cabelo da personagem. No caso de Cá dentro, uma das mais recentes publicações da editora, o código de barras, apesar de colorido a vermelho, o que o destacaria na imagem, converte-se, em resultado da composição global em sobrancelha de uma das duas personagens cujos rostos ocupam a contracapa do livro.

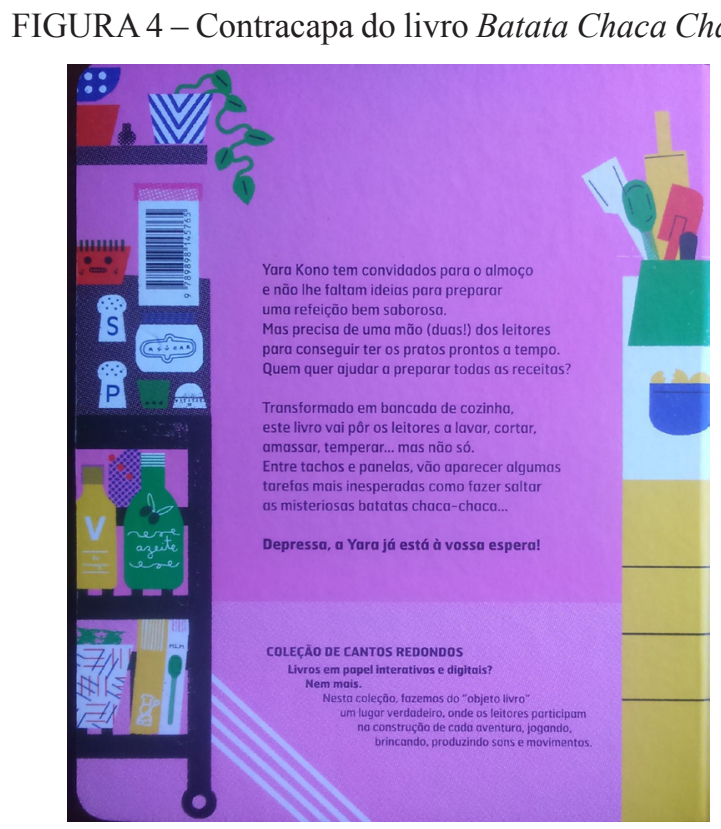

Fonte: KONO. Batata Chaca Chaca. 
Finalmente, atente-se num conjunto de códigos que exprimem a vertente mais original e criativa da editora, desafiando, através do questionamento, muitas vezes de cariz irónico, o leitor. Convertidos em ilustração única ou central das contracapas onde surgem, os códigos de barras ilustrados parecem perder a sua função original, numa clara subversão, com consequências ao nível da sugestão humorística, das regras, passando a integrar o sistema comunicativo do livro. Transformados em toalha de praia, toalha de mesa, nave espacial, vasos de flores, cão, tubarão, peixe, bota, inseto, árvore, livro, dirigível, nuvem ou camisola, os códigos de barras, mais ou menos destacados ou ocultos nas novas funções, estabelecem relações de afinidade implícita ou explícita com o conteúdo das narrativas, exigindo uma leitura capaz de estabelecer esse diálogo. Em alguns volumes, como Pê de pai (Figura 5), com texto de Isabel Minhós Martins e ilustrações de Bernardo Carvalho, a descoberta dessa relação exige algum esforço, procurando a articulação com o título e com o senso comum. Filho de peixe sabe nadar é uma proposta, aproveitando também o facto de a letra $P$ ser também a primeira de peixe, além da de pai. O tubarão, em Praia mar, parece contrastar, sob a forma de uma antítese, com o interior idílico do álbum sem palavras, sugerindo que também há outras dimensões deste elemento.

Já em $O$ mundo num segundo, dos mesmos autores, a proposta apresentada constitui um exercício diferente de inferência. O dirigível, enquanto objeto voador, surge associado à proposta do álbum, permitindo conhecer o mundo, ainda que não todo num segundo, recriando igualmente um determinado contexto histórico associado à história da aviação. No caso de $O$ caderno vermelho da rapariga karateca, o código de barras constitui referência ao caderno, elemento central da narrativa, reforçando a sugestão vertiginosa da mise en abîme que estrutura a publicação. 
FIGURA 5 - Contracapa do livro Pê de pai

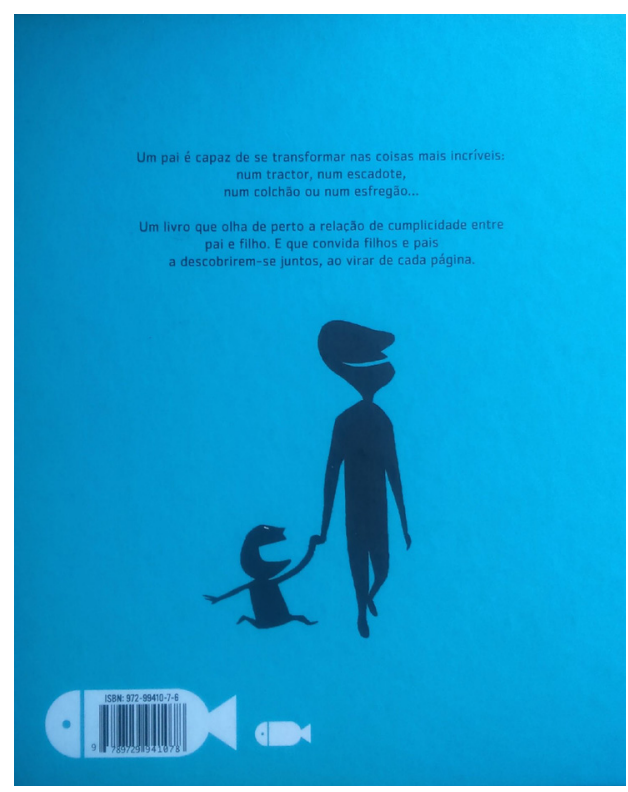

Fonte: MARTINS. Pê de pai.

Na sua globalidade, ao promoverem uma atenção a elementos peritextuais do livro infantil e juvenil ilustrados, os códigos de barras, alvo de algum tipo de manipulação gráfica e plástica, constituem piscadelas de olhos aos leitores mais atentos, desafiando-os a procurarem relações de sentido entre conteúdo e forma, mas também a integrarem, no processo de leitura, a materialidade do livro. Integrando vários aspetos, tanto de cariz mais lúdico como mais questionador, próximos do universo metaficcional, a ilustração dos códigos é também reveladora da inexistência de limites, físicos ou outros, à inventividade criativa de ilustradores e designers, explorando todas as possibilidades das publicações.

\section{Considerações finais}

Para além das referências já apresentadas, é relevante notar que muitos outros criadores se deixaram seduzir pelas possibilidades significativas (e também lúdicas) deste elemento identificador. Alguns deles recorrem à manipulação criativa dos códigos de forma mais assídua, pelo que este elemento se inscreve como identificador de algumas 
poéticas criativas pessoais. É o caso de Tom Lichtenheld, ilustrador norte-americano, autor de várias obras (Figura 6), onde os códigos de barras são alvo de algum tipo intervenção.

FIGURA 6 - Contracapa do livro Pato! Coelho!

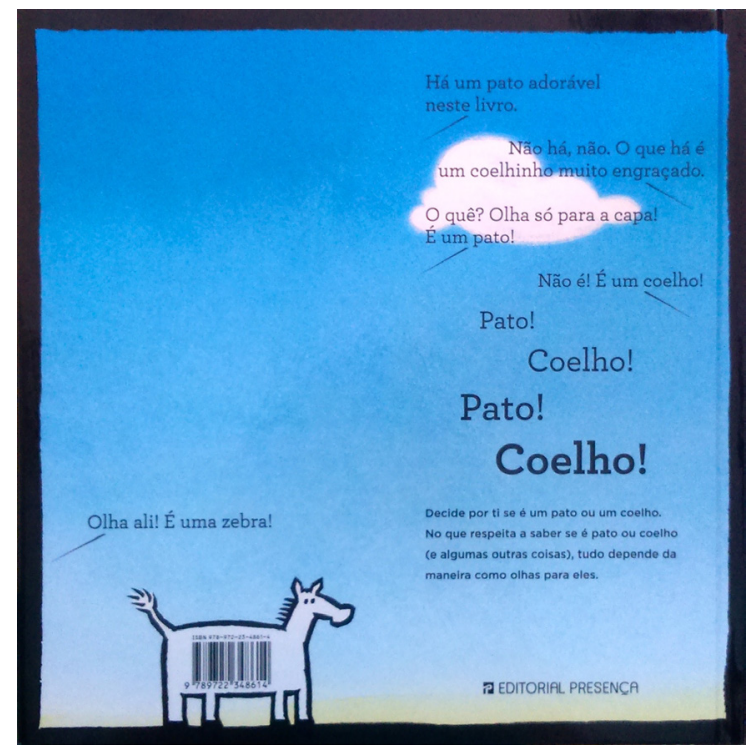

Fonte: ROSENTHAL. Pato! Coelho!

Os casos aqui analisados, a que se poderão juntar outros, sublinham, desde logo, o relevo da intervenção do designer gráfico no livro infantil ilustrado, em particular no livro-álbum, investindo claramente no seu processo de criação e conceção, transformando-o num objeto artístico, num artefacto de elevada qualidade estética. Mas esta aposta na exploração da materialidade não é incompatível com o investimento na dimensão lúdica, de que a ilustração dos códigos de barras, alvo de uma espécie de processo de desconstrução e/ou subversão, exemplificam. $\mathrm{O}$ cariz assumidamente experimental destas propostas evidencia o espaço de liberdade em que o livro-álbum se transforma, permitindo ao criador a manipulação livre e completamente criativa de todos os seus elementos.

No caso da ilustração dos códigos de barras, há vários elementos que se cruzam: por um lado, os criadores "atrevem-se" a brincar (desconstruir ou recriar) um elemento perfeitamente "externo" ao livro, 
mostrando que não há limites para a expressão artística e criativa; por outro, chamam a atenção do leitor para o relevo da ilustração, reensinado a sua leitura e interpretação, já que a alfabetização nos retira competências de análise profunda das imagens e dos seus significados. Trata-se, defendemos, de mais um elemento que revela bem a complexidade crescente das propostas oferecidas neste segmento editorial, com aproximações mais ou menos veladas e pensadas ao universo pósmoderno, visíveis no recurso à ilustração como contraponto, no relevo da metaficção e dos jogos intertextuais, através da mise en abîme, da metalepse ou da paródia, por exemplo, com destaque para procedimentos que assentam na autorreflexividade, como acontece claramente com os códigos de barras.

Concluo enumerando algumas daquelas que me parecem ser as principais vantagens "didáticas" ou formativas do contacto com publicações com estas características, sobretudo no que diz respeito ao desenvolvimento de competências precoces de leitura profunda que o adulto mediador de leitura deve incentivar: a promoção da realização de inferências, antecipações e de negociações de sentido próprias do processo de leitura literária sugerida pelos peritextos; a realização de ligações intertextuais e interartísticas relevantes sugeridas pelas ilustrações; a participação ativa e colaborativa do leitor no ato de leitura e na construção dos sentidos do texto, promovendo a interatividade que deve sempre marcar o processo de leitura; o desenvolvimento de competências complexas em termos de literacia visual, de elaboração de pensamento crítico e de estratégias interpretativas; e a descoberta das regras de funcionamento da ficção. E o contacto assíduo com experiências ricas e diversificadas de leitura pode bem ser o segredo para a formação de leitores competentes.

\section{Agradecimentos}

A autora do texto agradece às editoras Planeta Tangerina, Orfeu Negro e Editorial Presença a autorização para o uso das imagens que ilustram este artigo. 


\section{Referências}

ABREU, João Gomes de. A ilha. Ilustrações de Yara Kono. Carcavelos: Planeta Tangerina, 2012.

DAVIE, Penelope. Are You Talking to Me?: Hailing the Reader in Indigenous Children's Literature. Papers: Explorations into Children's Literature, v. 16, n. 2, p. 112-117, 2006.

DÍAZ ARMAS, Jesús. El contrato de lectura en el álbum: paratextos y desbordamiento narrativo. Primeras Noticias, Logroño, n. 222, p. 33-40, 2006.

DÍAZ ARMAS, Jesús. Estratégias de desbordamiento en la ilustración de libros infantiles. In: VIANA, F. L. et al. (Org.). Leitura, literatura infantil e ilustração: investigação e prática docente. Braga: Centro de Estudos da Criança - Universidade do Minho, 2003. p. 171-180.

GENETTE, Gérard. Palimpsestes. Paris: Seuil, 1987.

HIGONNET, Margaret R. The Playground of the Peritexts. Children's Literature Association Quarterly, v. 15, n. 2, p. 47-49, 1990. DOI: https:// doi.org/10.1353/chq.0.0831.

JONKER, Travis. Gallery: The Art of the Picture Book Barcode. 100 Scope Notes, 18 de março 2015. Disponível em: <http://100scopenotes. com/2015/03/18/gallery-the-art-of-the-picture-book-barcode/>. Acesso em: 22 mar. 2017.

KONO, Yara. Batata Chaca Chaca. Ilustrações de Yara Kono. Carcavelos: Planeta Tangerina, 2016.

LINDEN, Sophie van der. Lire l'album. Le Puy-en-Velay: Atelier du poisson soluble, 2007.

LOCH-WOUTERS, Marge. The Art of the Picture Book Barcode. Youth Services Shout-Out: YSS Blog, 2 Jan. 2016. Disponível em: <http:// yssevents.blogspot.pt/2016/01/the-art-of-picture-book-barcode.html $>$. Acesso em: 22 mar. 2017.

LOPES, Rui. Aqui há gato! Ilustrações de Renata Bueno. Lisboa: Orfeu Negro, 2017. 
LUZ, Ana Mafalda Carmo Pereira da. Do projecto à edição infantil: Lupa Design e Planeta Tangerina. 2010. Dissertação (Mestrado em Design de Comunicação) - Faculdade de Arquitectura da Universidade Técnica de Lisboa, Lisboa, 2010.

MARTINS, Isabel Minhós. Com o tempo. Ilustrações de Madalena Matoso. Carcavelos: Planeta Tangerina, 2014.

MARTINS, Isabel Minhós. Pê de pai. Ilustrações de Bernardo P. Carvalho. Carcavelos: Planeta Tangerina, 2006.

MATTOS, Margareth Silva de. As cintas e seus contratos de comunicação: envolvendo livro e público leitor. Texto apresentado no III Seminário Internacional de Estudos sobre Discurso e Argumentação (III SEDiAr), Universidade Federal de Sergipe - Brasil, 2016, Disponível em $<$ https:// www.researchgate.net/publication/306460487_AS_CINTAS_E_SEUS CONTRATOS_DE_COMUNICACAO_ENVOLIVENDO_LIVRO_E_PUBLICO_LEITOR $>$. Acesso em: 22 mar. 2017.

MATTOS, Margareth Silva de. Escritores consagrados, ilustradores renomados, palavra e imagem entrelaçadas: ingredientes de contratos de comunicação literários renovados. 2017. 346 f. Tese (Doutorado em Estudos da Linguagem) - Instituto de Letras, Universidade Federal Fluminense, Niterói, 2017.

MATTOS, Margareth Silva de; RIBEIRO, Patrícia Ferreira Neves; VIANNA, Sabrina. Capas e contracapas de livros ilustrados: espaços privilegiados de estratégias discursivas, Cadernos de Letras da UFF Dossiê: A crise da leitura e a formação do leitor, v. 52, p. 349-372, 2016.

PIMENTA, Rita. Um rei chato que acabou a tomar banhos de sol. Público, 29 de abril de 2017. Disponível em: <http://www.publico. $\mathrm{pt} /$ multimedia/video/um-rei-chato-que-acabou-a-tomar-banhos-desol-20170428-104037>. Acesso em: 11 set. 2017.

RAMOS, Ana Margarida. A ilustração para além das ilustrações: a leitura do livro infantil como um todo. In: EDUCAÇÃO e Leitura - Atas do Seminário. Esposende: Câmara Municipal de Esposende; Biblioteca Municipal Manuel de Boaventura, 2006. p. 55-67. 
RAMOS, Ana Margarida. Ilustrar para além das ilustrações: o contributo dos paratextos. In: GONZÁLEZ VIDA, Reyes, MOLEÓN VIANA, Miguel Ángel; GONZÁLEZ CASTRO, Carmen (Ed.). Atas del I Congreso Internacional Arte, Ilustración y Cultura Visual en Educación Infantil y Primaria: construcción de identidades. Granada: Universidade de Granada, 2010. p. 487-492.

ROSEnTHal, Amy Krouse. Pato! Coelho! Ilustrações de Tom Lichtenheld. Barcarena: Editorial Presença, 2012.

ROZARIO, Rebecca Anne C do. Consuming Books: Synergies of materiality and narrative in picturebooks. Children's Literature, v. 40, n. 1, p. 151-166, 2012.

SANTOS, Rui Paulo Vitorino dos. O influxo da mudança no álbum ilustrado: a influência da gramática visual. Porto: Faculdade de Belas Artes da Universidade do Porto, 2015.

SAUER, Tammi. Picture Book Barcode Bonanza. Picture Book Builders, 17 Apr 2015. Disponível em: <http://picturebookbuilders.com/2015/04/ picture-book-barcode-bonanza/>. Acesso em: 22 mar. 2017.

SIPE, Lawrence; MCGUIRE, Caroline E. Picturebook Endpapers: Resources for Literary and Aesthetic Interpretation, Children's Literature in Education, Pennsylvania n. 37, p. 291-304, 2006.

SOTTO MAYOR, Gabriela. As folhas de rosto nos livros ilustrados de literatura infantojuvenil: uma proposta tipológica. Tropelías: Revista de Teoría de la Literatura y Literatura Comparada, n. 25, p. 335-352, 2016.

Recebido em: 29 de maio de 2017. Aprovado em: 14 de agosto de 2017. 